\title{
Awareness campaigns as survival tools in the fight against gender-based violence in peri-urban communities of Bulawayo in Zimbabwe
}

\begin{tabular}{|c|c|}
\hline $\begin{array}{l}\text { Authors: } \\
\text { Glory Damba }{ }^{1} \\
\text { Wilfred Lunga } \\
\text { Charles Musar }\end{array}$ & urwa $^{3}$ \\
\hline $\begin{array}{l}\text { Affiliations: } \\
{ }^{1} \text { Ministry of W } \\
\text { Gender and C } \\
\text { Development, }\end{array}$ & $\begin{array}{l}\text { omen Affairs, } \\
\text { mmunity } \\
\text { Zimbabwe }\end{array}$ \\
\hline $\begin{array}{l}{ }^{2} \text { African Centr } \\
\text { Studies, North } \\
\text { University, So }\end{array}$ & $\begin{array}{l}\text { for Disaster } \\
\text { West } \\
\text { th Africa }\end{array}$ \\
\hline $\begin{array}{l}{ }^{3} \text { Department } \\
\text { and Social Scie } \\
\text { Education, Un } \\
\text { Botswana, Bot }\end{array}$ & $\begin{array}{l}\text { f Languages } \\
\text { nces } \\
\text { versity of } \\
\text { swana }\end{array}$ \\
\hline $\begin{array}{l}\text { Corresponden } \\
\text { Glory Damba }\end{array}$ & ce to: \\
\hline $\begin{array}{l}\text { Email: } \\
\text { glorydamba@ }\end{array}$ & yahoo.com \\
\hline $\begin{array}{l}\text { Postal addres } \\
20 \text { Kay Avenue } \\
\text { Somerton, Bul } \\
\text { Zimbabwe }\end{array}$ & $\begin{array}{l}\text { West } \\
\text { awayo, }\end{array}$ \\
\hline $\begin{array}{l}\text { Dates: } \\
\text { Received: } 20 \text { L } \\
\text { Accepted: } 11 \text { J } \\
\text { Published: } 10\end{array}$ & $\begin{array}{l}\text { ec. } 2012 \\
\text { an. } 2013 \\
\text { Apr. } 2013\end{array}$ \\
\hline $\begin{array}{l}\text { Keywords: } \\
\text { domestic viole } \\
\text { prevention; av } \\
\text { health probler }\end{array}$ & $\begin{array}{l}\text { nce; women; } \\
\text { lareness; } \\
\text { רs }\end{array}$ \\
\hline $\begin{array}{l}\text { How to cite th } \\
\text { Damba, G., Lur } \\
\text { Musarurwa, C. } \\
\text { 'Awareness car } \\
\text { survival tools i } \\
\text { against gender } \\
\text { in peri-urban c } \\
\text { of Bulawayo in } \\
\text { Jàmbá: Journa } \\
\text { Risk Studies 5( } \\
5 \text { pages. http:/ } \\
\text { org/10.4102/ja }\end{array}$ & $\begin{array}{l}\text { is article: } \\
\text { ga, W. \& } \\
\text { 2013, } \\
\text { npaigns as } \\
\text { the fight } \\
\text {-based violence } \\
\text { ommunities } \\
\text { Zimbabwe', } \\
\text { of Disaster } \\
\text { 2), Art. \#83, } \\
\text { dx.doi. } \\
\text { mba.v5i2.83 }\end{array}$ \\
\hline $\begin{array}{l}\text { Note: } \\
\text { 1st Biennial Co } \\
\text { Southern Afric } \\
\text { Disaster Reduc } \\
09 \text { to } 11 \text { Octok } \\
\text { Potchefstroom }\end{array}$ & $\begin{array}{l}\text { nference, } \\
\text { an Society for } \\
\text { tion (SASDiR), } \\
\text { er 2012, } \\
\text {, South Africa. }\end{array}$ \\
\hline 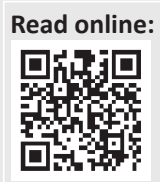 & $\begin{array}{l}\text { Scan this QR } \\
\text { code with your } \\
\text { smart phone or } \\
\text { mobile device } \\
\text { to read online. }\end{array}$ \\
\hline
\end{tabular}

Most of Zimbabwe's urban settlements owe their existence to mining activities; hence most peri-urban communities around Bulawayo, Zimbabwe's second largest city, are mining communities. However, research in these mining communities has shown that there is little focus on the strengthening of community dynamics that help members to cope with the challenges associated with Gender-Based Violence. Psychosocial support rarely arrives in time to effectively cover gaps left by traditional coping strategies. This paper presents and discusses experiences and insights accumulated from awareness campaigns meant to sensitise people about the nature and scope of gender-based violence. This article is a culmination of focus group discussions, informal interviews and participant observation as efforts were made towards capacity building for community members' abilities to identify forms of risky behaviour associated with gender-based violence, and the appropriate actions members could take should they find themselves in such situations. In short, this article discusses the conceptualisation of domestic and gender violence as a risk, forms of gender-based violence, the rationale behind campaigns to reduce the internalisation of gender-based violence, and challenges faced in inculcating behaviour change efforts.

\section{Introduction}

Concerns about the high incidence of violence against women in Zimbabwe have prompted researchers and activists to undertake studies to assess the extent and nature of the problem with a view to coming up with measures to address it. Zimbabwe's Ministry of Women Affairs, Gender and Community Development, has a mandate to raise awareness with people about genderbased violence. This is also enshrined in the United Nations (UN) (United Nations 1979) and Southern Africa Development Community (SADC) (Southern Africa Development Community 2008) protocols, both of which focus on the curbing of such violence.

Most violence against women in Zimbabwe is domestic and included amongst the perpetrators are consensual partners, members of the women's families and other close acquaintances. Studies on gender-based violence indicate that most cases of domestic violence revolve around the maintenance of men's economic and social control over women. However, there has been little discussion of how societal transformation, alterations in family forms and changed life experiences exacerbate domestic violence and/or limit measures to put an end to it. Domestic violence features frequently amongst other crimes such as assault, incest, rape and murder in contemporary Zimbabwe and has devastating effects, not just on the victim, but on other family members as well.

Despite women and men having equal rights and status in most countries, violence against women is still rampant and many homes have remained torture chambers for women (Kira 2004). In Zimbabwe, the social, political and economic instability has led to increased vulnerability of women and girls, who are especially susceptible to domestic and sexual violence and abuse. Interestingly, domestic violence remains the most common form of violence against women in both developed and developing countries (Mookodi 2004). In the Southern Africa Development Community (SADC), mainstreaming gender into an action and community-building initiative has become the cornerstone for economic growth and sustainable development. Whilst some progress has undoubtedly been made in the SADC region in terms of improving public awareness and giving women who suffer from violence more options to turn to, some women in member states continue to suffer violence at the hands of abusive partners. Experiences of Zimbabwean life have shown that women continue to face extraordinarily high levels of violence, particularly in mining communities. 


\section{Unpacking the concept 'gender- based violence'}

Domestic violence, which inevitably is gender based, is a pattern of assault and coercive behaviour. It can be physical, sexual and psychological, by a person against his or her own intimate partner. However, women are more frequently the victims. Physical abuse and rape are the most common forms of such violence. As defined by the European Union 'violence against women' is:

any act of gender-based violence that results in, or is likely to result in, physical, sexual or psychological harm or suffering to women, including threats of such acts, coercion or arbitrary deprivation of liberty, whether occurring in public or in private life. (Zimbabwe 2010)

Violence against women occurs in both private and public spheres and is done by people who claim to love these women. It cuts across age, colour, creed, political affiliation and economic, social or political status, and occurs in almost all geographical locations. In another dimension, the most vulnerable are those with physical, mental or other challenges, but the bottom line is that every woman is a potential victim of some form of violence.

Patriarchy creates gender inequality resulting in women's subordination as well as causing conflict in families (Fox \& Luxton 1993; Thome \& Yalom 1982). These inequalities also extend to the access to resources. Throughout the world women have lower incomes than men and limited access to fixed assets such as land and other forms of property that could be used for income generation. Mookodi (2004) reviews literature from a number of writers in which a conclusion is made that in Botswana patriarchal practices are embedded in public, political and family-based decision-making practices in socio-legal systems and in inheritance customs. Many of these patriarchal practices are related to violence against women.

A classical analysis by Parsons and Bales (1955) is still valid. The analysis divides gender activities into instrumental (production roles; production of goods and services) for man and expressive (reproduction roles, child-bearing and -rearing, emotional support, etc.) for women (Fox \& Luxton 1993; Parsons \& Bales 1955). The key criticism levelled against this perspective is that it does not acknowledge conflict and competition within domestic settings and overemphasises the complementary nature of the gender division. However, gender division of labour perpetuates men's control over women's labour, particularly with regard to social reproduction (child-bearing and child-rearing) and domestic 'duties' for family members (Hartmann 1981).

At the personal or household level, inequality involves emotional abuse, threats and actual use of physical force. At the societal and community levels, tradition, culture and religion reinforce the injustice of discrimination and exploitation of women and rationalise it as a national state of affairs. At state level, women are denied equal citizenship, civil, political and, very significantly, economic equality. Moreover, it is known that most women will not disclose violence in their relationship without being asked.

Strategies for addressing gender-based violence face particular challenges in resource-poor rural areas where, for most women, there is little or no access to safe shelters, counselling services, or the judicial system. In this context, awareness campaigns represent a critical opportunity to begin addressing gender-based violence through community organisations and local leaders.

\section{Awareness campaign objectives}

The awareness campaigns were aimed at sensitising people about what gender-based violence really is. The campaigns also sought to educate people about the forms of genderbased violence and actions they can take should they find themselves in such situations, as well as seeking to reduce the internalisation of gender-based violence as a way of life through behaviour change amongst the people. Amongst other things, the campaigns had the following specific objectives. They sought to:

- determine people's awareness of what gender-based violence is

- enlighten people on forms of gender-based violence

- educate people on what actions to take if they are victims of gender-based violence

- seek behaviour change amongst the perpetrators and victims of gender-based violence

- curb the increase of gender-based violence issues through the use of a campaign of zero tolerance.

The objectives determined the subject matter or topics that were covered in workshops. This included differentiating domestic violence from gender-based violence, by identifying its forms and the actions to take when one is a victim of gender-based violence. Discussions also focused on factors associated with causes of gender-based violence and ways to avoid these forms of violence.

\section{How the data on the campaigns were collected}

Qualitative research techniques were employed. In qualitative research, subjectivity and involvement of the researcher are part of the research process (Bogdan \& Biklen 1992; Lincoln \& Guba 1985), hence tools that required the in-depth participation of the researchers were used. These included an interview-based questionnaire that was designed to capture information on the gender-based violence, in 10 different workshops, in the mining settlements around the city of Bulawayo. The settlements included Old Nick Mine, Hope Fountain, How Mine and Shangani Mine. The workshops were also characterised by the viewing and analysing of films on gender-based violence, group discussions, and informal interviews. In essence, the use of various tools to gather data enabled the researchers to engage in some form of triangulation, thereby enhancing validity and reliability. The 
qualitative approach was meant to enable the researcher to obtain and interpret informants' meanings, perceptions, and experiences on gender-based violence in a natural setting in order to encourage the participants to speak out as much as possible without fear (Neuman 2000).

A film that realistically depicted the nature and consequences of domestic violence was viewed and subsequently discussed. Care was taken to create an environment of safety and confidentiality, and individual, peer, and group counselling were made available throughout the training. The participants in the workshops ranged between 30 to 40 men and women. The justification of including men was that whilst the awareness targeted women, men as the perpetrators of such violence needed to be involved because they are part of the equation. Most men did not attend the workshops due to work commitments and some were resting after working night shifts. There were more women than men (approximately three women for every one man, a ratio of 3:1). Participation was voluntary and participants were assured of their anonymity as part of the ethical considerations (Smythe \& Murray 2000). Follow-up assistance was offered for identified problems.

\section{Emerging issues}

Initially, there was a tendency to speak about gender-based violence with professional detachment, as a phenomenon which the participants wished to be better able to address on their own. As the days progressed, however, the experiences and insights became much more personal and emotional, and toward the end, an opportunity was created for both men and women to relate their own experiences of gender-based violence. Observations are that many of the cases of genderbased violence, such as issues of power, control and authority by men over women, are largely based on traditional norms and values. It is a tradition that men exercise power, authority and control over women. On the other hand, in cases where men are victims of violence, they have also failed to disclose such problems because, traditionally, any man who discloses that he has been assaulted by his wife is viewed as weak. Thus men have the highest number of unreported cases of gender-based violence. In addition, issues such as sexual assault cannot be discussed outside the family. Thus most men have failed to report cases of gender-based violence, all in the name of tradition.

As argued by Frey, Botan and Friedman (1992) in Chesebro and Borisoff (2007), qualitative data take the form of words rather than numbers, thus allowing qualitative data to help come up with concepts, themes and patterns on the participants' perceptions of gender-based violence (Chesebro \& Borisoff 2007). A number of issues emerged from this campaign and are discussed in this section.

During focus group discussions there was much animation about how women would respond if they discovered that their own relatives were abused by their husbands. These responses were interesting because they suggested how the participants might deal with an abusive situation. At one mine, indications were that the community suffers from an extremely high incidence of domestic violence because of the nature of the compound housing arrangement. Gossiping is common in mine compounds and women often team up to beat up those suspected of having love affairs with other women's husbands. Most victims of gender-based violence agreed that they have been raped by their husbands several times. They also indicated that those who refused their husbands' conjugal rights often suffered economic and physical abuse as a result. At another mine, it was discovered that a lot of abuse is perpetrated on children of all age groups. Eighty-five percent of the women who attended the workshop agreed that they were economically abused by their spouses and that most of their husbands had extramarital affairs. This exposed them to the risk of HIV infection. They could not insist on the use of a condom by the husbands, since, in most cases, the husbands argued that they have the final say on the use of condoms, since they paid lobola (the 'bride price'). In some cases, domestic violence was a result of suspected infidelity and jealousy by both parties.

Examining the discussions, it would seem that the workshops were fruitful for both men and women. Women seemed to view marital rape as legitimate whilst male participants got an opportunity to assess the experiences of the female folk as well as examining their own beliefs and behaviours.

With regard to marital rape, the majority of men felt that rape within marriage is not possible. In fact, one man admitted that seeing the film during the training had really challenged his prior beliefs. Amongst the 31 female participants, 22 had experienced at least one form of abuse by an intimate partner. Some of the participants also expressed that they have been abusive to an intimate partner, have engaged in physical and/or sexual abuse, and have been emotionally or psychologically abusive.

\section{Survivors or perpetrators of violence}

Focus group discussions revealed women's personal experiences of abuse either as survivors or as perpetrators. Although they were not directly questioned about this, the nature of the comments strongly suggested that this was a common experience for women in mining communities. Amongst the women, there was an initial tendency to discuss domestic violence as something that only happened to other, usually less educated, people. One young woman stated confidently: 'It's nowadays that we are becoming aware of our rights. That is why it's very much rare [sic] to find a professional person being abused.'

However, as the discussions evolved and became more animated, the comments also became increasingly personal. For example, with regard to economic abuse, the women revealed that in spite of their education and professional status, they were still obliged to hand over their salaries to their husbands at the end of each month and felt unable to exert meaningful control over their own finances. In fact, 
because many had to depend on their husbands in order to attend some form of education, they found that the men now claimed this as a justification for the total control of family finances.

A pattern which emerged gradually from the focus groups was that women may be at greater risk of abuse by virtue of their professional status. Many described the situation in which a husband began to feel threatened by his professional, income-earning wife, resulting in tension and, often, violent. Moreover, because it was considered 'completely unacceptable' for a married woman to be seen as befriending a male colleague, they found themselves under constant scrutiny and suspicion of sexual infidelity, which could then lead to physical assaults from their husbands. One woman described: 'In a working situation there are more males. So if they find you with a male colleague, then you are "in love" with this one ... and, you will have bruises every day.'

Other important findings were that, culturally, women are supposed to treat abuse as part of marriage. They have to soldier on even in the face of abuse and violence. Rarely are men or women keen to turn to the police or judicial system. Most women preferred to resolve issues within the family rather than refer the abused woman to the judicial system. All agreed that such abuse was a private matter. However, some statements reflected the underlying belief that women thought they might have done something to deserve the beating. The sentiments raised were that the problem lies with women, hence there was need to give advice to women so that they would not repeat behaviour that attracts abuse or violence.

\section{Attitudes and beliefs regarding physical abuse}

Amongst men, references to physical abuse were frequently described using terms such as 'discipline'. In discussing when they felt it was justified to beat a woman, there was a general consensus amongst men that when the women do not listen, they get beaten. There was a feeling that a woman's perceived shortcomings in meeting household chores or minding children, justified discipline. Some men indicated that they did not tolerate laziness, hence there was need to beat the women at least once. Similarly, women participants indicated that a man who is known to be beating his wife is often generally regarded with approval as one who knows how to discipline his wife and keep his home in order. Such men are regarded in mining communities as the 'right man'. In this sense, violence against women has become socially normalised. Most women feel that it is normal behaviour for men to be violent. However, both men and women argued that violence was neither appropriate nor justifiable in solving or managing conflict.

Certain behaviours such as abuse of alcohol, 'disrespectful attitude', and a wife's sexual infidelity were identified as potential causes of gender-based violence. It is interesting to note that it is the wife's infidelity and not the husband's that triggers violence at home. The subject of sexual infidelity was raised repeatedly in every workshop and focus group discussion. Men and women stated that a husband's infidelity was socially accepted and even encouraged. In fact, it is widely regarded as a man's right to have extramarital affairs. It was noted that a woman's lack of cooperation in accommodating these relationships might be a cause for her physical abuse. Infidelity on the part of a woman, however, was judged to merit physical assault so as to act as a deterrent or to re-shape her behaviour. Even amongst the women participants, many expressed the opinion that a woman's sexual infidelity might justify punishment and that, in the case of adultery, relatives would not be against the man. The conclusion is thus: women are bound to be beaten as they are not allowed to be unfaithful, but they must entertain a man's extramarital affairs.

\section{Attitudes and beliefs regarding sexual abuse}

There was a marked disparity between men and women with regard to definitions of sexual abuse. Women participants agreed that rape within marriage was possible, whilst men denied it. Women also tended to take a broader perspective of sexual abuse, which encompassed sexual harassment and a man's disregard for a woman's own sexual needs. Whilst some female participants felt that women were not to blame, others believed that women were raped because they tended to put themselves at risk, for example through the way they dressed. Amongst male participants, sexual abuse was perceived only in terms of rape perpetrated by a stranger and therefore the notion of marital rape was largely dismissed.

\section{Attitudes and beliefs regarding psychological abuse}

Unlike men, women frequently describe gender-based violence in terms of emotional or psychological abuse, referring to situations in which a man might constantly insult (verbal abuse) or undermine a woman. Others described such abuse in terms of a husband's behaving with complete disregard for his wife's feelings, for example restricting her social movements (isolation) whilst enjoying his freedom to socialise without her. There were reports of incidents where a man brought another woman home and forced his wife to share their matrimonial bed with the girlfriend. This is indeed psychological abuse.

\section{Recommendations}

Recommendations include continued capacity building programmes that will sensitise women regarding their sexual and reproductive health rights. Both men and women in mining communities should have access to information in local languages. There is a need to review and reform laws that protect the sexual and reproductive health rights of women. Both men and women need to be involved in these programmes involving gender, sexual rights and reproductive health.

Engagement of communities in participatory processes to identify community-based strengths and resources, to help 
them prevent violence, and to identify coping mechanisms to support (rather than stigmatise) survivors is needed. This might include identifying how the current community policing initiatives could be better received and supported by communities.

Community mobilisation and individual behaviour change levels have to be put in place. These include raising overall community awareness, mobilising community-based efforts, and providing support for evidence-based advocacy; and conducting mass media campaigns that improve knowledge (using billboards, television, papers and mobile phones), attitudes, and practices of community members. This should include developing mechanisms to monitor, report, and seek redress for violations such as rape and other forms of sexual violence, exploitation and trafficking. There is a need to prioritise a softer approach for advocacy and/or sensitisation in lieu of action. Whilst there has been emphasis on ensuring that survivors can access services through the victim-friendly units at the police and courts, access to health and psychosocial services has received less attention.

Relevant ministries and institutions need to integrate prevention of and response to gender-based violence and other gender equality concerns into their emergency preparedness and response plans. A multisectoral approach involving health, psychosocial, protection and legal and/ or justice sectors is urgently needed. Lastly, the need to resolve conflict between customary and codified law, and to repeal discriminatory laws, is critical. Equal access to justice and protection before the law is important and therefore citizenship, marriage and family laws must be reviewed as well as putting in place adequate sanctions against those who violate the provisions of such laws.

\section{Conclusion}

The workshops were indeed fruitful as they enabled open discussions on issues of gender-based violence and ways to curb it, as well as mapping out response mechanisms. There was consensus that behaviour change is needed if gender-based violence was to be minimised or eradicated. At least people are now aware of the differences between rights and abuse. Using the observations drawn from this programme, it can be concluded that tradition and culture play an important part in causing gender-based violence. It is a result of the patriarchal system that views men as superior to women, hence creating an environment of inequality, stereotypes and a recipe for violence. This is supported by misinterpretations of religious scriptures, which glorify the superiority of men over women. Even with modernisation, the problem has remained entrenched through unclear policies and conventions. The answer seems to lie in setting up a knowledgeable society where traditions and culture are questioned.

Knowledge of available modes of response is essential and a prerequisite for action, meaning that awareness campaigns are a step nearer to setting up a knowledgeable society where gender-based violence is not tolerated.

\section{Acknowledgments Competing interests}

The authors declare that they have no financial or personal relationship(s) which may have inappropriately influenced them in writing this article.

\section{Authors' contributions}

G.D. (Ministry of Women Affairs, Gender and Community Development) performed the focus group discussions and compiled the data on people's views on gender based violence. All three authors were involved in the planning of the awareness campaigns, focus group discussions, and the analysis of data based on people's views on gender-based violence, as well as writing the final report and article on the findings.

\section{References}

Bogdan, R.C. \& Biklen, S.K., 1992, Qualitative research in education, Allyn and Bacon, Boston.

Chesebro, J.W. \& Borisoff, D.J., 2007, 'What makes qualitative research qualitative?', Qualitative Research Reports in Communication 8, 3-14. http://dx.doi. org/10.1080/17459430701617846

Fox, B. \& Luxton, M., 1993, 'Conceptualising Family', in B. Fox (ed.), Family Patterns: Gender Relations, pp. 19-29, Oxford, Toronto.

Hartmann, H., 1981, 'The Family as the Locus of Gender, Class and Political Struggle: The Example of Housework', Signs 6, 366-394. http://dx.doi.org/10.1086/493813

Kira, I., 2004, 'Assessing and responding to secondary traumatisation in the survivors' families', Torture 14, 38-45.

Lincoln, Y.S. \& Guba, E.G., 1985, Naturalistic inquiry, Sage, Beverley Hills.

Mookodi, G., 2004, 'The dynamics of domestic violence against women in Botswana', Pula: Botswana Journal of African Studies 18(1), 55-64.

Neuman, W.L., 2000, Social Research Methods: Qualitative and Quantitative Approaches, Allyn and Bacon, Needham Heights, MA.

Parsons, T. \& Bales, R.F., 1955, Family, Socialisation and Interaction Process, Free Press, New York.

Smythe, W.E. \& Murray, M.J., 2000, 'Owning the story: ethical considerations in narrative research', Ethics and Behavior 10, 311-313. http://dx.doi.org/10.1207/ narrative research',
S15327019EB1004_1

Southern Africa Development Community, 2008, SADC Protocol on Gender and Development, Gaborone: SADC.

Thome, B. \& Yalom, M., 1982, Rethinking the Family: Some Feminist Questions, Longman, New York.

United Nations, 1979, Convention on the elimination of all forms of discrimination against women (CEDAW/C/2006/II/4), UN General Assembly, New York.

Zimbabwe, 2010, Report on the Study on the Socio-Economic Implications of Violence Against Women in Zimbabwe, Government Printer, Harare. 